\title{
Preparation of Polymer Nanoparticles via Phase Inversion Temperature Method Using Amphiphilic Block Polymer Synthesized by Atom Transfer Radical Polymerization
}

\author{
Yusuke Sasaki, Michinari Kohri, Takashi Kojima, Tatsuo Taniguchi* and Keiki Kishikawa \\ Division of Applied Chemistry and Biotechnology, Graduate School of Engineering, Chiba University, \\ 1-33 Yayoi-cho, Inage-ku, Chiba 263-8522, JAPAN \\ *Tel: +81-43-290-3409, E-mail: taniguchi@faculty.chiba-u.jp
}

\begin{abstract}
We report the first synthesis of polymer nanoparticles employing the phase inversion temperature (PIT) method using a polymeric surfactant. Oil-in-water nanoemulsions were prepared by the PIT method using amphiphilic comb-like block polymer (polystyrene-b-poly[oligo(ethylene glycol) methyl ether methacrylate], PSt- $b$-POEGMA) as a polymeric surfactant, and subsequently St droplets were polymerized. PSt- $b$-POEGMA was synthesized by sequential atom transfer radical polymerization of St and OEGMA. The interfacial property of PSt- $b$-POEGMA in aqueous media was investigated by surface tension measurement and fluorescence probe technique. Monodisperse PSt nanoparticles with $50 \mathrm{~nm}$ in diameter were obtained by a free radical polymerization of St droplets initiated by the water-soluble initiator.

Key words: phase inversion temperature (PIT) / polymeric surfactant / amphiphilic block polymer / atom transfer radical polymerization (ATRP) / polymer nanoparticles
\end{abstract}

\section{INTRODUCTION}

Polymer nanoparticles with less than $100 \mathrm{~nm}$ in diameter have a transparent or translucent appearance due to their droplet size below the wavelength of visible light. Also, the stability of a particle increases as the droplet size decreases according to the Stokes-Einstein equation. Thus, polymer nanoparticles have been attracting much attention in the industrial field, such as coating materials, cosmetics, and biomaterials $[1,2]$.

Nowadays, polymer nanoparticles with less than $100 \mathrm{~nm}$ in diameter can be prepared mainly by three major techniques. In emulsion and microemulsion polymerization, polymer particles are generated in the continuous phase via homogeneous or micellar nucleation [3]. In contrast, the process of miniemulsion polymerization is based on transformation of monomer droplets into polymer particles (monomer droplet nucleation) without mass transport [4]. Miniemulsion polymerization is thus used for encapsulation of functional molecules. However, preparation of miniemulsions generally requires a high input of mechanical energy using the apparatus such as a high pressure homogenizer, an ultrasonic sonicator, and so on.

Low energy emulsification techniques without the use of high shear forces have been developed recently [5]. These techniques are based on phase transition due to a change in the curvature of the surfactant as a result of the variations in environmental conditions. One of the most employed low energy emulsification techniques is the phase inversion temperature (PIT) method reported by Shinoda and Saito [6]. It is based on the changes in affinity of nonionic surfactants incorporating poly(ethylene oxide) (PEO) with temperature. Since a nonionic surfactant has a positive curvature and becomes hydrophilic at low temperature, the oil-in-water $(\mathrm{O} / \mathrm{W})$ emulsion can be obtained spontaneously. On the other hand, at high temperature, a nonionic surfactant has a negative curvature and becomes hydrophobic due to dehydration of PEO chains, resulting in formation of a water-in-oil (W/O) emulsion. At intermediate temperature (the PIT), the curvature becomes zero and a bicontinuous microemulsion or a lamellar liquid crystalline phase appears. The interfacial tension is extremely low at the PIT, and hence very small-sized nanoemulsions are prepared. Recently, several reports have demonstrated polymerization of nanoemulsions obtained by low energy emulsification techniques.

Magdassi and Spernath reported for the first time that lauryl acrylate nanoemulsions obtained by the PIT method were polymerized using a redox initiator [7]. They prepared nanoparticles in the size range of $50-120 \mathrm{~nm}$, depending on the hydrophile-lipophile balance (HLB) and the concentration of nonionic surfactants. In addition, they prepared functional nanoparticles encapsulating pyrene. Puig et. al. reported that hexyl methacrylate nanoemulsions obtained by the PIT method were polymerized using a redox initiator after emulsification with a nonionic surfactant [8]. They studied the detailed polymerization kinetics such as the particle size, the conversion, and the molecular weight. However, no work has been published on polymerization of nanoemulsions obtained by low energy emulsification techniques using the polymeric surfactant containing hydrophilic and hydrophobic components.

Amphiphilic block polymers have become increasingly important in recent years due to their self-assembly and special chemical structures. Amphiphilic block polymers with low polydispersities and tailor-made chemical structures can be synthesized by controlled/living radical polymerization (CRP) techniques. CRP techniques enabled us to prepare amphiphilic block polymers for different purposes and specific targeted applications. In particular, atom transfer radical polymerization (ATRP) is regarded as the most versatile technique among CRP because of the broad range of monomers and easily adjustable polymerization rates [9].

PEO has been widely used as a nonionic hydrophilic block since PEO is a biocompatible nontoxic polymer with potential applications as biomaterials. Armes and co-workers synthesized well-defined poly[oligo(ethylene glycol) methyl methacrylate] (POEGMA) [10]. Heuts et. al. 
Scheme 1. (A) Synthetic route of $\mathrm{PSt}_{21}-b$-POEGMA ${ }_{41}-\mathrm{Cl}$ amphiphilic block polymer by ATRP (B) Preparation of PSt nanoparticles through the PIT method using $\mathrm{PSt}_{21}-b$-POEGMA ${ }_{41}-\mathrm{Cl}$ amphiphilic block polymer as a polymeric surfactant

(A)

A)

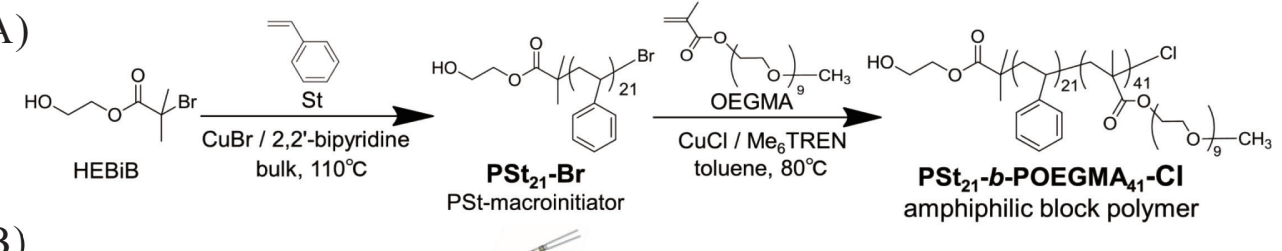

(B)
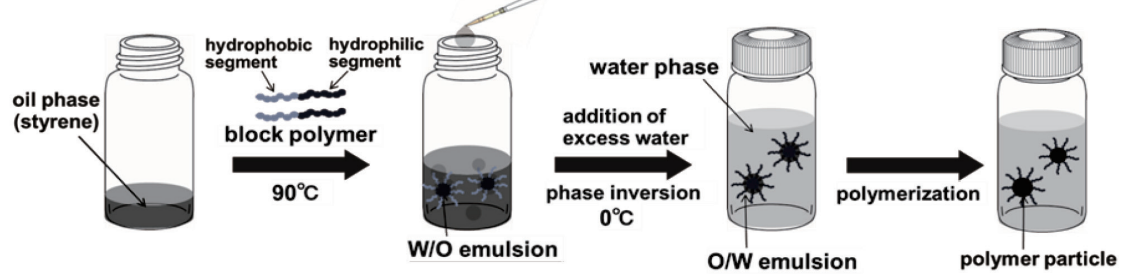

reported preparation of polystyrene (PSt) particles with about $400 \mathrm{~nm}$ in diameter by emulsion polymerization using PSt- $b$-POEGMA amphiphilic block polymer as a polymeric surfactant [11].

Herein, we prepare PSt nanoparticles with less than 100 $\mathrm{nm}$ in diameter through the PIT method using PSt- $b$-POEGMA amphiphilic block polymer and then explore a new strategy for the polymerization of low-energy made nanoemulsions using a polymeric surfactant. The PSt nanoparticles are prepared in two steps: First, $\mathrm{PSt}_{21}$ - $b$-POEGMA ${ }_{41}$-Cl amphiphilic block polymer was synthesized by ATRP according to the synthetic route in Scheme 1A. Second, St nanodroplets were prepared by the PIT method using $\mathrm{PSt}_{21}-b$-POEGMA ${ }_{41}-\mathrm{Cl}$ amphiphilic block polymer as a polymeric surfactant, and subsequently PSt nanoparticles were obtained by a free radical polymerization of St droplets initiated by a water-soluble initiator 2,2'-azobis[2-(2-imidazolin-2-yl)propane] dihydrochloride (VA044) according to the synthetic route in Scheme 1B.

\section{EXPERIMENTAL}

\subsection{Materials}

2-Hydroxyethyl-2-bromoisobutyrate (HEBiB) and tris[2-( $N, N$-dimethylamino)ethyl]amine $\left(\mathrm{Me}_{6} \mathrm{TREN}\right)$ were prepared according to the procedure described in the literatures $[12,13]$. St purchased from Kanto Chemical was distilled under reduced pressure. OEGMA $\left(M_{\mathrm{n}}=468\right.$ g/mol) kindly supplied by Shin-Nakamura Chemical was passed through an alumina column. Other chemical reagents were used without further purification.

\subsection{Synthesis of polystyrene macroinitiator $\left(\mathrm{PSt}_{21}-\mathrm{Br}\right)$ by ATRP}

St (9.37 g, $90 \mathrm{mmol}), \operatorname{HEBiB}(0.957 \mathrm{~g}, 4.5 \mathrm{mmol})$, and 2,2'-bipyridine $(2.11 \mathrm{~g}, 13.5 \mathrm{mmol})$ were placed into a Schlenk flask. The solution was deoxygenated by repetitive freeze-pump-thaw cycles, followed by addition of $\mathrm{CuBr}(0.642 \mathrm{~g}, 4.5 \mathrm{mmol})$. The reaction mixture was heated at $110^{\circ} \mathrm{C}$ and stirred under nitrogen. After $1 \mathrm{~h}$, the flask was rapidly cooled. The sample was diluted in excess THF and then precipitated in methanol. The product was dried in vacuo prior to GPC and NMR analyses.

\subsection{Synthesis of amphiphilic block polymer (PSt $t_{21}$-b-POEGMA ${ }_{41}$-Cl) by ATRP}

OEGMA (7.02 g, $15 \mathrm{mmol}), \mathrm{PSt}_{21}-\mathrm{Br}(0.657 \mathrm{~g}, 0.30$ mmol), $\mathrm{Me}_{6}$ TREN (0.138 g, $\left.0.60 \mathrm{mmol}\right)$, and toluene (12 $\mathrm{mL})$ were placed into a Schlenk flask. The solution was deoxygenated by repetitive freeze-pump-thaw cycles, followed by the addition of $\mathrm{CuCl}(0.030 \mathrm{~g}, 0.30 \mathrm{mmol})$. The polymerization was carried out at $80^{\circ} \mathrm{C}$ under nitrogen atmosphere. After $4 \mathrm{~h}$, the flask was rapidly cooled. The sample was diluted in excess THF and passed through an alumina column. The solution was concentrated and then precipitated in hexane.

\subsection{Self-assembly of the amphiphilic block polymer in aqueous media}

The micellar solutions were prepared as follows: $\mathrm{PSt}_{21}-b$-POEGMA 41 -Cl $(0.10 \mathrm{~g})$ was dissolved in toluene $(0.10 \mathrm{~mL})$, and subsequently deionized water $(10 \mathrm{~mL})$ was added. The solution was heated at $90^{\circ} \mathrm{C}$ for 10 min with vigorous stirring and then rapidly cooled in an ice bath. Toluene was removed under reduced pressure for two days as monitored by ${ }^{1} \mathrm{H} \mathrm{NMR}$.

\subsection{Polymerization of nanoemulsions obtained by the PIT method using amphiphilic block polymer as a surfactant}

The block polymer was dissolved in the oil phase. Crude $\mathrm{O} / \mathrm{W}$ emulsions were prepared by mixing the oil and water phases. The emulsions containing $8 \%(\mathrm{w} / \mathrm{w})$ oil phase (St) and $4 \%(\mathrm{w} / \mathrm{w})$ surfactant $\left(\mathrm{PSt}_{21}-b\right.$-POEGMA $\left.41-\mathrm{Cl}\right)$. The crude $\mathrm{O} / \mathrm{W}$ emulsions $(1.4 \mathrm{~g})$ were heated at $90^{\circ} \mathrm{C}$ where the inversion to $\mathrm{W} / \mathrm{O}$ emulsions occurred and then rapidly cooled in an ice bath, resulting in $\mathrm{O} / \mathrm{W}$ nanoemulsions. The water-soluble initiator (VA044) was then added to the O/W nanoemulsion. The prepolymer solution was subjected to nitrogen bubbling for $10 \mathrm{~min}$ in an ice bath and sealed off. Polymerization was carried out at $40^{\circ} \mathrm{C}$ for $6 \mathrm{~h}$. The monomer conversion was obtained by gravimetry.

\subsection{Characterizations}

Molecular weights of polymers were determined by gel permeation chromatography (GPC) using a TOSOH TSKgel $\alpha 3000$ column with DMF as the eluent at a flow rate of 0.6 $\mathrm{mL} / \mathrm{min}$ at $40^{\circ} \mathrm{C}$. PSt standards were used for calibration. The ${ }^{1} \mathrm{H}$ NMR spectra were recorded with a JEOL JNM-ECA500 Fourier transform NMR spectrometer using $\mathrm{CDCl}_{3}$ as a solvent. The surface tension of block polymer aqueous solutions was measured by a SEO Phoenix Alpha P-200 contact angle analyzer at $25^{\circ} \mathrm{C}$. Surfaceware 7 was used as an analysis software of the pendant drop method. Fluorescence spectra were measured on a JASCO FP-750 spectrometer. Pyrene and block polymer concentrations in the final solutions were $5.0 \times 10^{-7} \mathrm{M}$ and $1.0 \times 10^{-4}-0.20$ $\mathrm{g} / 100 \mathrm{~mL}$, respectively. The excitation wavelength was set 
Table 1. Molecular weight for $\mathrm{PSt}_{21}$-Br macroinitiator and $\mathrm{PSt}_{21}-b$-POEGMA ${ }_{41}-\mathrm{Cl}$ block polymer synthesized by ATRP

\begin{tabular}{cccccccc}
\hline Sample & {$[\mathrm{M}] /[\mathrm{I}]$} & $M_{\mathrm{n} \text { theory }}{ }^{\mathrm{a}}$ & $M_{\mathrm{n} \mathrm{NMR}}{ }^{\mathrm{b}}$ & $M_{\mathrm{n} \mathrm{GPC}}{ }^{\mathrm{c}}$ & $M_{\mathrm{w}} / M_{\mathrm{n}}{ }^{\mathrm{c}}$ & conversion $^{\mathrm{d}}$ & terminal Br $^{\mathrm{b}}[\%]$ \\
\hline $\mathrm{PSt}_{21}-\mathrm{Br}$ & 20 & 1770 & 2190 & 2230 & 1.18 & 85 & 96 \\
$\mathrm{PSt}_{21}-b-\mathrm{POEGMA}_{41} \mathrm{Cl}$ & 50 & 17200 & 21400 & 18500 & 1.45 & 64 & - \\
\hline
\end{tabular}

${ }^{\mathrm{a}}$ Calculated by $([\mathrm{M}] /[\mathrm{I}]) \times$ conversion $\times M_{\text {monomer }} \cdot{ }^{\mathrm{D}}$ Determined by ${ }^{1} \mathrm{H}$ NMR spectra. ${ }^{\mathrm{c}}$ Measured by GPC: $\alpha 3000, \mathrm{DMF}, 40{ }^{\circ} \mathrm{C}$,

$0.6 \mathrm{~mL} / \mathrm{min}$, PSt standards. ${ }^{\mathrm{d} D e t e r m i n e d ~ b y ~}{ }^{1} \mathrm{H}$ NMR spectra of polymers without purification.

Table 2. Interfacial properties of $\mathrm{PSt}_{21}-b$-POEGMA $41-\mathrm{Cl}$ amphiphilic block polymer

\begin{tabular}{|c|c|c|c|c|c|c|c|c|}
\hline Sample & $\begin{array}{c}\mathrm{CMC}_{\mathrm{ST}}{ }^{\mathrm{a}} \\
{[\mathrm{g} / 100 \mathrm{~mL}]}\end{array}$ & $\begin{array}{l}\mathrm{CMC}_{I 1 / / 3}{ }^{\mathrm{a}} \\
{[\mathrm{g} / 100 \mathrm{~mL}]}\end{array}$ & $\begin{array}{c}\gamma_{\mathrm{cmc}} \\
{[\mathrm{mN} / \mathrm{m}]}\end{array}$ & $\begin{array}{c}\Gamma^{\mathrm{b}} \\
{\left[\mathrm{mol} / \mathrm{m}^{2}\right]}\end{array}$ & $\begin{array}{c}A^{\mathrm{c}} \\
{\left[\mathrm{nm}^{2} / \text { molecule }\right]}\end{array}$ & $\begin{array}{l}I_{1} / I_{3} \\
{[-]}\end{array}$ & $\begin{array}{l}D_{\mathrm{h}}{ }^{\mathrm{d}} \\
{[\mathrm{nm}]}\end{array}$ & $\begin{array}{c}T_{\mathrm{c}}^{\mathrm{e}} \\
{\left[{ }^{\circ} \mathrm{C}\right]}\end{array}$ \\
\hline $\mathrm{PSt}_{21}-b$-POEGMA ${ }_{41}-\mathrm{Cl}$ & $2.7 \times 10^{-3}$ & $3.2 \times 10^{-3}$ & 52.8 & $1.5 \times 10^{-6}$ & 1.1 & 1.13 & $22 \pm 9$ & 78.8 \\
\hline
\end{tabular}

${ }^{a}$ Critical micelle concentration (CMC): determined by surface tension measurement and fluorescence probe technique. ${ }^{\text {v}}$ Surface excess concentration $(\Gamma)$ : calculated by slope of surface tension versus block polymer concentration (eq. 1). ${ }^{\mathrm{c}}$ Occupied area $(A)$ : determined by surface excess concentration (eq. 2). ${ }^{\mathrm{d}}$ Hydrodynamic diameter of block polymer micelles measured by DLS. ${ }^{\mathrm{e}}$ Cloud point $\left(T_{\mathrm{c}}\right)$ : determined by transmittance measurement.

at $322 \mathrm{~nm}$. The CMC value was obtained from plots of the $I_{1} / I_{3}$ emission intensity ratios $\left(I_{1}\right.$ and $I_{3}$ are the emission intensities at 373 and $383 \mathrm{~nm}$, respectively) versus block polymer concentration. The cloud point of the block polymer aqueous solution was measured on a Hitachi U-3210 spectrophotometer. Transmittance at $670 \mathrm{~nm}$ was monitored as a function of temperature at fixed concentration of block polymer $(0.10 \mathrm{~g} / 100 \mathrm{~mL})$. The size distributions of the micelles and particles were measured by an Otsuka ELSZ-1000ZSCK light scattering apparatus at $25^{\circ} \mathrm{C}$. Scanning electron microscopy (SEM) micrographs were obtained using a JEOL JSM-6510A operating at $20 \mathrm{kV}$.

\section{RESULTS AND DISCUSSION}

\subsection{Synthesis of the amphiphilic block polymer $\left(\mathrm{PSt}_{21}-\mathrm{b}\right.$-POEGMA $\mathrm{A}_{41}$-Cl)}

Polymerization of OEGMA using PSt-macroinitiator has previously been reported by Heuts and co-worker [11]. They used halogen exchange technique to obtain a good control of polymerization. In this technique, a bromide-type initiator was successfully extended with a more reactive monomer by using $\mathrm{CuCl}$ instead of $\mathrm{CuBr}$ [14].

GPC measurement revealed that $\mathrm{PSt}_{21}-b$-POEGMA ${ }_{41}-\mathrm{Cl}$ block polymer with a narrow molecular weight distribution was successfully synthesized. The molecular weights of $\mathrm{PSt}_{21}-\mathrm{Br}$ macroinitiator and $\mathrm{PSt}_{21}-b$-POEGMA ${ }_{41}-\mathrm{Cl}$ block polymer determined by both ${ }^{1} \mathrm{H}$ NMR and GPC analyses were summarized in Table 1. Experimental molecular weights of polymers synthesized by ATRP were in agreement with theoretical values predicted from the ratio of monomer to initiator. Polymerization of St was stopped at $<90 \%$ conversion to prevent bromide chain ends from becoming dead ends. Recent work has indicated that halide chain-end functionality at a high monomer conversion $(>$ $90 \%$ ) is significantly reduced [15].

\subsection{Interfacial properties of the amphiphilic block polymer in aqueous media}

The block polymer obtained in this study was not directly soluble in water. Therefore, the micellar solution was prepared by mixing deionized water and the block polymer dissolved in organic solvent above the cloud point, followed by cooling and the removal of organic solvent.

Critical micelle concentration (CMC) of the synthesized block polymer was investigated by surface tension measurement and fluorescence probe technique using pyrene. As given in Fig. 1, the surface tention at the $\mathrm{CMC}_{\mathrm{ST}}(2.7 \times$ $10^{-3} \mathrm{~g} / 100 \mathrm{~mL}$ ) was $52.8 \mathrm{mN} / \mathrm{m}$, while the abrupt decrease of
$I_{1} / I_{3}$ occurred at $3.2 \times 10^{-3} \mathrm{~g} / 100 \mathrm{~mL}$, which is considered as the $\mathrm{CMC}_{I 1 / / 3}$. $I_{1} / I_{3}$ of the aqueous $\mathrm{PSt}_{21}-b-\mathrm{POEGMA}_{41}-\mathrm{Cl}$ solution in a low and a high concentration range were 1.43 and 1.13 , respectively. It should be noted that $I_{1} / I_{3}$ below the $\mathrm{CMC}_{I 1 / I 3}$ was lower than that in water (1.9). This might be attributed to formation of unimers [16].

Applying the Gibbs adsorption isotherm equation (eq. 1), we calculated the surface excess concentration $(\Gamma)$.

$$
\Gamma=-1 / R T(d \gamma / d \ln C) \quad(\text { eq. } 1)
$$

Here, $\gamma$ is surface tension in $\mathrm{mN} / \mathrm{m}, R$ is the gas constant $(8.314 \mathrm{~J} / \mathrm{mol} \cdot \mathrm{K}), T$ is the temperature in Kelvin, $\Gamma$ is the surface excess concentration in $\mathrm{mol} / \mathrm{m}^{2}$, and $C$ is the concentration in $\mathrm{mol} / \mathrm{L}$. The average area per molecule at the interface $(A)$ can be obtained from $\Gamma$ (eq. 2).

$$
A=1 / N_{\mathrm{A}} \Gamma
$$

Here, $N_{\mathrm{A}}$ is Avogadro's number.

The size of block polymer micelles was measured by DLS. Particle size distribution showed a monomodal distribution, where the peak corresponded to the micelle formation, and no large aggregates were observed. The hydrodynamic diameter $\left(D_{\mathrm{h}}\right)$ of block polymer micelles was determined to be $22 \mathrm{~nm}$ by DLS (see Table 2, Fig. 2).

The cloud point $\left(T_{\mathrm{c}}\right)$ of block polymer was verified by transmittance measurement. The block polymer obtained in this study displayed a $T_{\mathrm{c}}$ at $78.8^{\circ} \mathrm{C}$ (see Table 2). The $T_{\mathrm{c}}$ of POEGMA homopolymer $(\mathrm{DP}=20)$ having side chains of 9 $\mathrm{EO}$ units was previously observed to be $90^{\circ} \mathrm{C}$ [17]. The

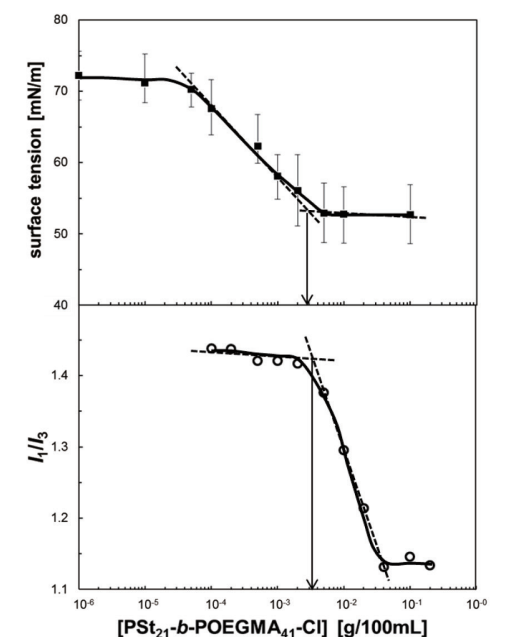

Fig. 1 Plots of surface tension and micropolarity parameter $\left(I_{1} / I_{3}\right)$ of $\mathrm{PSt}_{21}-b$-POEGMA $41-\mathrm{Cl}$ aqueous solution as a function of block polymer concentration. 

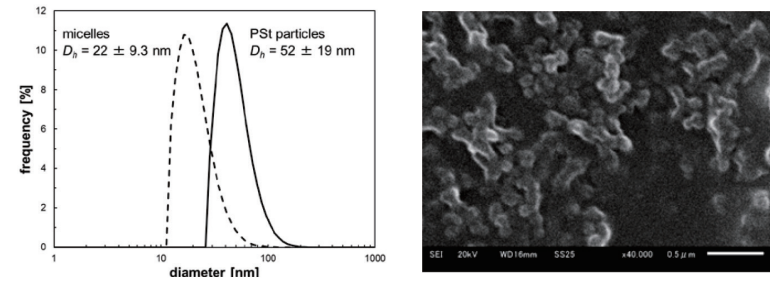

Fig. 2 Size distribution (left) and SEM image (right) of PSt particles prepared by a free radical polymerization of St droplets after emulsification with the $\mathrm{PSt}_{21}-b$-POEGMA $41-\mathrm{Cl}$ block polymer.

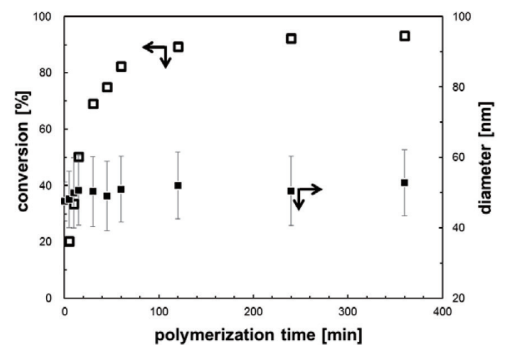

Fig. 3 Conversions and diameters in a free radical polymerization of St droplets after emulsification with $\mathrm{PSt}_{21}-b-\mathrm{POEGMA}_{41}-\mathrm{Cl}$ as a function of polymerization time.

introduction of hydrophobic PSt chains lowered the solubility of block polymer in water due to the unfavorable interactions between water and hydrophobic PSt chains.

\subsection{Polymerization of nanoemulsions obtained by the PIT method using block polymer as a polymeric surfactant}

Polymerization of monomer droplets has to occur at temperature lower than the $T_{\mathrm{c}}$ in order to retain the stability of droplets. The conversions of St were investigated as a function of polymerization time (see Fig. 3). The St monomer consumption in the polymerization initiated by VA044 proceeded rapidly, and the conversion of St reached a constant value six hours. In general, a hydrophobe has to be added in order to diminish Ostwald ripening by reducing the diffusion of monomer, when nanoemulsions were prepared $[4,8]$. In this study, though the nanoemulsions were made in the absence of the hydrophobe, the nanoemulsion did not grow in the observing period. It was likely that the diffusion of monomer between droplets was reduced by dissolution of hydrophobic PSt chains in monomer droplets. It is worth mentioning that a polymeric surfactant effectively retards the broadening in particle size distribution with time due to Ostwald ripening when nanoemulsions were prepared by the PIT method. The size distribution of PSt particles after completion of the polymerization at $360 \mathrm{~min}$ was measured by DLS (see Fig. 2). Hydrodynamic diameter of PSt particles was $52 \mathrm{~nm}$. The produced latexes exhibited a high dispersion stability over two months.

The SEM image of PSt particles obtained by the polymerization of $\mathrm{St}$ droplets emulsified with $\mathrm{PSt}_{21}-b$-POEGMA ${ }_{41}-\mathrm{Cl}$ block polymer was shown in Fig. 2. While the particles had fuzzy edges due to the low $T_{\mathrm{g}}(-56$ to $-59^{\circ} \mathrm{C}$ ) of the POEGMA [18], the particles displayed spherical shapes.

\section{CONCLUSION}

In this paper, we report the polymerization of monomer nanodroplets prepared via the PIT method using $\mathrm{PSt}_{21}-b$-POEGMA ${ }_{41}-\mathrm{Cl}$ amphiphilic brush-type block polymer synthesized by ATRP. NMR and GPC measurements confirmed the successful synthesis of block polymer. The surface activity and the self-assembly behavior of the block polymer was investigated by surface tension measurement and fluorescence probe technique. The CMC and the $T_{c}$ of the synthesized block polymer were determined to be $3.0 \times 10^{-3} \mathrm{~g} / 100 \mathrm{~mL}$ and $79^{\circ} \mathrm{C}$, respectively. Monodisperse PSt nanoparticles with $50 \mathrm{~nm}$ droplet size were obtained by a free radical polymerization of St droplets initiated by water-soluble initiator (VA044) after emulsification with $\mathrm{PSt}_{21}-b$-POEGMA ${ }_{41}-\mathrm{Cl}$ block polymer. To the best of our knowledge, this is the first report on polymerization of low-energy made nanoemulsions using a polymeric surfactant. The availability of a polymeric surfactant was demonstrated for preparation of polymer nanoparticle through the PIT method with suppressed Ostwald ripening.

\section{REFERENCES}

[1] J. M. Asua, Polymeric dispersions. Principles and applications, Dordrecht: Kluwer (1997).

[2] V. Mailander, K. Landfester, Biomacromolecules, 10, 2379-2400 (2009).

[3] C. S. Chern, Principles and Applications of Emulsion Polymerization, Wiley: Hoboken, New Jersey (2008).

[4] M. Antonietti, K. Landfester, Prog. Polym. Sci., 27, 689-757 (2002).

[5] A. Maali, M. T. Hamed Mosavian, J. Dispers. Sci. Technol., 34, 92-105 (2013).

[6] K. Shinoda, H. Saito, J. Colloid Interface Sci., 26, 70-74 (1968).

[7] L. Spernath, S. Magdassi, Polym. Adv. Technol., 18, (> $90 \%$ within $120 \mathrm{~min}$. In addition, particle size as a function of polymerization time for St droplets was shown in Fig. 3. The particles sizes remained constant with time in the observing period of 705-711 (2007).

[8] A. G. Alvarado, J. Nolla, M. Rabelero, L. A. Pérez-Carrillo, M. Arellano, E. Mendizábal, C. Solans, J. E. Puig, J. Macromol. Sci., Part A: Pure Appl. Chem., 50, 385-391 (2013).

[9] K. Matyjaszewski, J. Xia, Chem. Rev., 101, 2921-2990 (2001).

[10] X. S. Wang, S. P. Armes, Macromolecules, 33, 6640-6647 (2000).

[11] A. Munoz-Bonilla, A. M. van Herk, J. P. A. Heuts, Macromolecules, 43, 2721-2731 (2010).

[12] S. Coca, P. Davis, P. Miller, K. Matyjaszewski, Polym. Prepr. (Am. Chem. Soc., Div. Polym. Chem.), 38, 689-690 (1997).

[13] J. Queffelec, S. G. Gaynor, K. Matyjaszewski, Macromolecules, 33, 8629-8639 (2000).

[14] K. Matyjaszewski, D. A. Shipp, J.-L. Wang, T. Grimaud, T. E. Patten, Macromolecules, 31, 6836-6840 (1998).

[15] J.-F. Lutz, K. Matyjaszewski, J. Polym. Sci., Part A: Polym. Chem., 43, 897-910 (2005).

[16]W. S. Shim, S. W. Kim, E.-K. Choi, H.-J. Park, J.-S. Kim, D. S. Lee, Macromol. Biosci., 6, 179-186 (2006).

[17] J.-F. Lutz, A. Hoth, Macromolecules, 39, 893-896 (2006).

[18] D. Abdelhamid, H. Arslan, Y. Zhang, K. E. Uhrich, Polym. Chem., 5, 1457-1462 (2014). 